\title{
Polychlorinated biphenyl (118) activates osteoclasts and induces bone resorption in goldfish
}

\author{
Koji Yachiguchi • Noriko Matsumoto • Yuki Haga • Motoharu Suzuki • \\ Chisato Matsumura • Masahiro Tsurukawa • Toshihiro Okuno • Takeshi Nakano • \\ Kimi Kawabe • Kei-ichiro Kitamura • Akira Toriba • Kazuichi Hayakawa • \\ Vishwajit S. Chowdhury • Masato Endo • Atsuhiko Chiba • Toshio Sekiguchi • \\ Masaki Nakano • Yoshiaki Tabuchi • Takashi Kondo • Shigehito Wada • \\ Hiroyuki Mishima • Atsuhiko Hattori • Nobuo Suzuki
}

Received: 17 September 2012 / Accepted: 16 November 2012 / Published online: 18 December 2012

(C) The Author(s) 2012. This article is published with open access at Springerlink.com

\begin{abstract}
To analyze the effect of polychlorinated biphenyl (PCB) 118 on fish bone metabolism, we examined osteoclastic and osteoblastic activities, as well as plasma calcium levels, in the scales of PCB (118)-injected goldfish. In addition, effect of PCB (118) on osteoclasts and osteoblasts was investigated in vitro. Immature goldfish, in which the
\end{abstract}

Responsible editor: Philippe Garrigues

K. Yachiguchi $\cdot$ N. Matsumoto $\cdot$ T. Sekiguchi $\cdot$ N. Suzuki $(\bowtie)$ Noto Marine Laboratory, Institute of Nature and Environmental

Technology, Kanazawa University, Ogi, Noto-cho,

Housu-gun, Ishikawa 927-0553, Japan

e-mail: nobuos@staff.kanazawa-u.ac.jp

Y. Haga $\cdot$ M. Suzuki $\cdot$ C. Matsumura $\cdot$ M. Tsurukawa $\cdot$ T. Okuno $\cdot$

T. Nakano

Hyogo Prefectural Institute of Environmental Sciences, Kobe,

Hyogo 654-0037, Japan

K. Kawabe $\cdot$ A. Toriba $\cdot$ K. Hayakawa

Faculty of Pharmaceutical Sciences, Institute of Medical,

Pharmaceutical and Health Sciences, Kanazawa University,

Kanazawa, Ishikawa 920-1192, Japan

K.-i. Kitamura

Faculty of Health Sciences, Institute of Medical, Pharmaceutical and Health Sciences, Kanazawa University, Kodatsuno, Ishikawa 920-0942, Japan

V. S. Chowdhury

International Education Center, Faculty of Agriculture, Kyushu

University, Fukuoka 812-8581, Japan

M. Endo

Graduate School of Marine Science and Technology, Tokyo University of Marine Science and Technology, Minato-ku, Tokyo

108-8477, Japan endogenous effects of sex steroids are negligible, were used. PCB (118) was solubilized in dimethyl sulfoxide at a concentration of $10 \mathrm{ppm}$. At 1 and 2 days after PCB (118) injection (100 ng/g body weight), both osteoclastic and osteoblastic activities, and plasma calcium levels were measured. In an in vitro study, then, both osteoclastic and

A. Chiba

Department of Materials and Life Sciences, Sophia University, Tokyo 102-8554, Japan

\section{Nakano - A. Hattori}

Department of Biology, College of Liberal Arts and Sciences, Tokyo Medical and Dental University, Ichikawa, Chiba 272-0827, Japan

Y. Tabuchi

Division of Molecular Genetics Research, Life Science Research Center, University of Toyama, Sugitani, Toyama 930-0194, Japan

\section{T. Kondo}

Department of Radiological Sciences, Graduate School of Medicine and Pharmaceutical Sciences, University of Toyama, Sugitani, Toyama 930-0194, Japan

S. Wada

Department of Oral and Maxillofacial Surgery, Faculty of Medicine, University of Toyama, Sugitani, Toyama 930-0194, Japan

H. Mishima

Department of Human Life Sciences, Kochi Gakuen College, Kochi 780-0955, Japan 
osteoblastic activities as well as each marker mRNA expression were examined. At 2 days, scale osteoclastic activity in PCB (118)-injected goldfish increased significantly, while osteoblastic activity did not change significantly. Corresponding to osteoclastic activity, plasma calcium levels increased significantly at 2 days after PCB (118) administration. Osteoclastic activation also occurred in the marker enzyme activities and mRNA expressions in vitro. Thus, we conclude that PCB (118) disrupts bone metabolism in goldfish both in vivo and in vitro experiments.

Keywords PCB (118) - Bone metabolism · Fish scales . Osteoclasts $\cdot$ Osteoblasts $\cdot$ Plasma calcium

\section{Introduction}

It has been reported that polychlorinated biphenyl (PCB) congeners act as endocrine-disrupting compounds (Lind et al. 2004a, b; Bovee et al. 2011; Nakayama et al. 2011; Ju et al. 2012). As bone formation and resorption are controlled by several hormones and vitamins (see a review, Peacock 2010), PCBs might disturb bone metabolism. In some animals, actually, the bone disruption caused by PCB has been reported (rat, Lind et al. 2004a; bear, Sonne et al. 2004; sheep, Gutleb et al. 2010; alligator, Lind et al. 2004b; turtle, Holliday and Holliday 2012; salmon, Olufsen and Arukwe 2011; zebrafish, Ju et al. 2012). In humans, changes in bone metabolism associated with exposure to PCBs have also been investigated (Hodgson et al. 2008). However, the direct effects of PCBs on osteoclasts and osteoblasts have not yet been elucidated in any animals.

The teleost scale is a calcified tissue that contains osteoblasts, osteoclasts, and the bone matrix of two layers (bony layer - a thin, well-calcified external layer; a fibrillary layer-a thick, partially calcified layer) (Bereiter-Hahn and Zylberberg 1993; Suzuki et al. 2000, 2007; Yoshikubo et al. 2005; Ohira et al. 2007). The bone matrix, which includes type I collagen (Zylberberg et al. 1992), osteocalcin (Nishimoto et al., 1992), and hydroxyapatite (Onozato and Watabe 1979), is present in the scale as well as in mammalian bone. Recently, we detected both cathepsin $\mathrm{K}$ and tartrate-resistant acid phosphatase (TRAP) mRNA expression in scale osteoclasts (Azuma et al. 2007). In osteoblasts, we detected osteoblast-specific markers, such as alkaline phosphatase (ALP), runt-related transcription factor 2, osterix, osteocalcin, type I collagen, and the receptor activator of the NF- $\mathrm{KB}$ ligand (RANKL) (Thamamongood et al. 2012). Therefore, the features of osteoclasts and osteoblasts in scales are similar to those in mammals.

In fish as well as mammals, plasma calcium level was regulated by hormones such as parathyroid hormone (Suzuki et al. 2011a) and calcitonin (Suzuki et al. 2000, 2004a). In an in vivo experiment, fugu parathyroid hormone I induced hypercalcemia resulted from the increase of both osteoblastic and osteoclastic activities in the scale and caused to decrease scale calcium contents (Suzuki et al. 2011a). Scale osteoclastic activation was also observed in the prostaglandin $\mathrm{E}_{2}$-injected goldfish (Omori et al. 2012). It is reported that the scales are a better potential internal calcium reservoir than the body skeletons, jaws, and otoliths, examined by the ${ }^{45} \mathrm{Ca}$-labeling study for the calcified tissues of goldfish and killifish (Mugiya and Watabe 1977). Thus, we conclude that teleost scale is an active and functional calcium reservoir.

In fish, PCB (118) is the highest congener compared with PCB-105, -156, -167, -123, -157, -114, -189, -77, -126, -81, or 169 (Bhavsar et al. 2007). Furthermore, it has been reported that trabecular bone mineral content was almost $30 \%$ lower in the PCB (118) (49 g/kg body weight/day) at the metaphysis in sheep (Gutleb et al. 2010), although the detail mechanism has not yet been elucidated. We therefore analyzed the effect of PCB (118) on scale osteoclastic and osteoblastic activities, as well as plasma calcium levels, in the goldfish scales. In addition, effect of PCB (118) on osteoclasts and osteoblasts was investigated in vitro. This is the first to demonstrate that $\mathrm{PCB}$ (118) activates osteoclasts and induced bone resorption in fish.

\section{Materials and methods}

\section{Animals}

To examine the effect of PCB (118) on the bone metabolism, immature goldfish (4-6g), in which the endogenous effects of sex steroids are negligible, were used for the in vivo study. A previous study (Suzuki et al. 2000) indicated that the sensitivity for calcemic hormones was higher in mature female than in mature male teleosts. Therefore, female goldfish (Carassius auratus) (30-40 g) were purchased from a commercial source (Higashikawa Fish Farm, Yamatokoriyama, Japan) and used for the in vitro experiments.

All experimental procedures were conducted in accordance with the Guide for the Care and Use of Laboratory Animals prepared by Kanazawa University.

Effects of PCB (118) on scale osteoclastic and osteoblastic activities and the plasma calcium in goldfish at day 1 and 2 after PCB (118) injection (in vivo experiment)

PCB (118) was solubilized in dimethyl sulfoxide (DMSO) at a concentration of $10 \mathrm{ppm}$. Goldfish (body weight 4-6 g) were anesthetized with ethyl 3-aminobenzoate and methanesulfonic acid salt (Sigma-Aldrich, Inc., MO, USA) and taken the blood (about $100 \mu \mathrm{l}$ ) from caudal vessels of each individual into heparinized syringes just before PCB (118) injection. After centrifugation at $15,000 \mathrm{rpm}$ for $3 \mathrm{~min}$, the plasma was immediately frozen and kept at $-80{ }^{\circ} \mathrm{C}$ until 
use. In the experimental group $(n=10)$, thereafter, PCB (118) was intraperitoneally injected (100 ng/g body weight). The goldfish in the control group $(n=10)$ were injected with DMSO in the same manner. These goldfish were kept in the aquarium for 1 and 2 days. During the experimental periods, these goldfish were not given any food to exclude intestinal calcium uptake from diets. Each day after injection, the scales were collected from each goldfish. At day 2 after injection, blood samples (about $100 \mu \mathrm{l}$ ) were collected from the gill using a heparinized capillary from individual, anesthetized goldfish. After centrifugation at 15,000 rpm for $3 \mathrm{~min}$, the plasma was also immediately frozen and kept at $-80{ }^{\circ} \mathrm{C}$ until use. The plasma total calcium level $(\mathrm{mg} / 100 \mathrm{ml})$ was determined using an assay kit (Calcium C; Wako Pure Chemical Industries, Ltd., Osaka, Japan). Then, we measured the activities of ALP and TRAP activities as respective indicators of each activity in osteoclasts and osteoblasts (Suzuki et al. 2000, 2009; Suzuki and Hattori 2002). The measurement methods (Suzuki et al. 2009) of ALP and TRAP activities were as follows. The incubated scale was transferred to its own well in a 96-well microplate after washing with saline. An aliquot of $100 \mu$ of an alkaline buffer $(100 \mathrm{mM}$ Tris- $\mathrm{HCl}, \mathrm{pH} 9.5 ; 1 \mathrm{mM}$ $\mathrm{MgCl}_{2} ; 0.1 \mathrm{mM} \mathrm{ZnCl}_{2}$ ) for ALP activity or an acid buffer ( $0.1 \mathrm{M}$ sodium acetate including $20 \mathrm{mM}$ tartrate, $\mathrm{pH}$ 5.3) for TRAP activity was added to each well. This microplate was frozen at $-80{ }^{\circ} \mathrm{C}$ immediately and then kept at $-20{ }^{\circ} \mathrm{C}$ until analysis. After thawing, an aliquot of $100 \mu \mathrm{l}$ of $20 \mathrm{mM}$ para-nitrophenyl-phosphate in an alkaline buffer or an acid buffer was added to each well. This plate was then incubated at $20{ }^{\circ} \mathrm{C}$ for $30 \mathrm{~min}$ with shaking. After incubation, the reaction was stopped by adding $50 \mu \mathrm{l}$ of a $3 \mathrm{~N} \mathrm{NaOH}-$ $20 \mathrm{mM}$ EDTA solution. Aliquots of $150 \mu \mathrm{l}$ of a colored solution were transferred to a new plate, and the absorbance was measured at $405 \mathrm{~nm}$. The absorbance was converted into the amount of produced para-nitrophenol (pNP) using a standard curve for pNP. After measurement of the absorbance, the ALP and TRAP activities were normalized by the surface area $\left(\mathrm{mm}^{2}\right)$ of each goldfish scale. The results are shown as the means $\pm \mathrm{SE}$ of eight scales.

PCB (118) contents in the scales of goldfish (in vivo experiment)

At day 1 and 2 after PCB (118) injection, the scales were collected from goldfish and then immediately frozen and kept at $-80^{\circ} \mathrm{C}$ until use. The PCB (118) contents were analyzed by the methods of Hirai et al. (2005). Because a single sample volume was very small, we conducted three measurements to obtain a pulled sample. Thus, the mean of three measurements was described in the results.

Effects of PCB (118) on osteoclastic and osteoblastic activities in the cultured scales of goldfish (in vitro experiment)

Scales collected from goldfish $(n=10)$ after anesthesia with ethyl 3-aminobenzoate and methanesulfonic acid salt (SigmaAldrich) and incubated for 6 and $18 \mathrm{~h}$ in Leibovitz's L-15 medium (Invitrogen, Grand Island, NY, USA) containing a $1 \%$ penicillin-streptomycin mixture (ICN Biomedicals, Inc., OH, USA) supplemented with PCB (118) $(0.025,0.25$, and $2.5 \mathrm{ppm})$. In an in vivo experiment, around 0.05 to $0.1 \mathrm{ppm}$ PCB was detected in the PCB-injected scales. Based on these PCB contents in the scales, we decided the administration doses of $\mathrm{PCB}$ in an in vitro experiment. The PCB concentration in one goldfish was performed using 48 scales from each left or right side. The 48 scales used in the present study were considered to use as follows: (1) eight scales for TRAP analysis by $0.025 \mathrm{ppm},(2)$ eight scales for TRAP analysis by $0.25 \mathrm{ppm}$, (3)
Fig. 1 Effects of PCB (118) injection on scale TRAP (a) and ALP (b) activities in goldfish. Each column and the vertical line represent the mean \pm SEM ( $n=10$ samples; one sample from one fish). ${ }^{* *}$ indicates statistically significant difference at $P<0.01$ from the values in the control a) TRAP activity

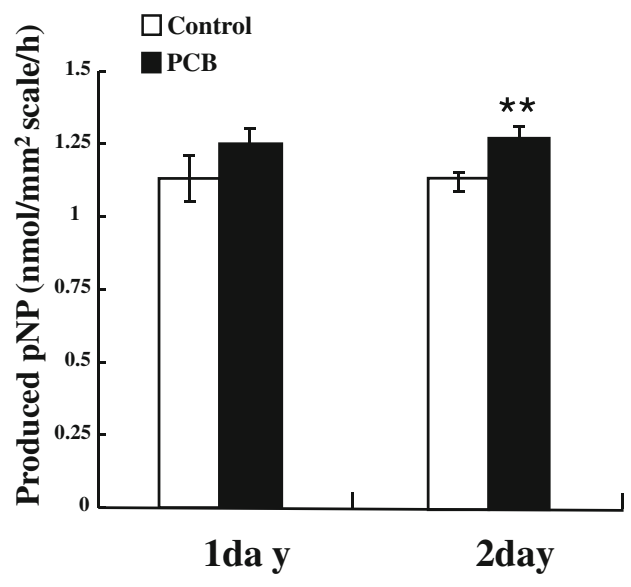

Experimental term after PCB injection

\section{b) ALP activity}

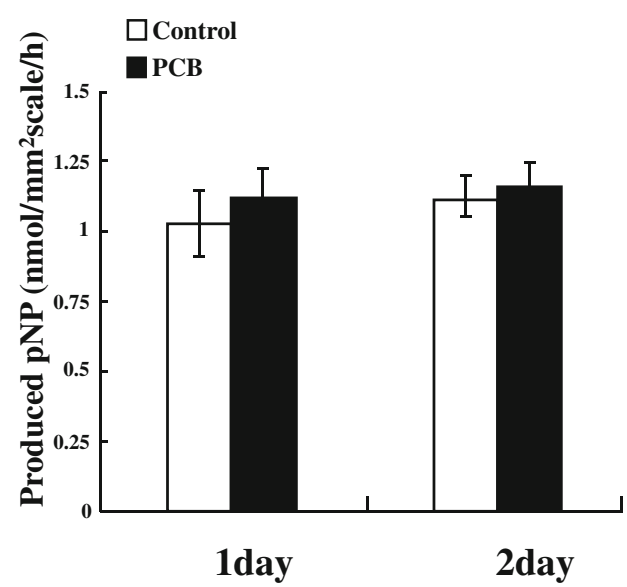

Experimental term after PCB injection 


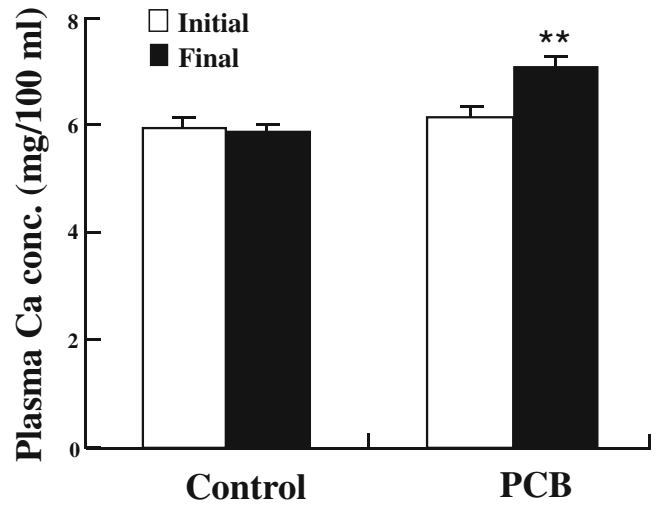

Fig. 2 Effects of PCB (118) injection on plasma calcium level (mg/ $100 \mathrm{ml}$ ) in goldfish. Each column and the vertical line represent the mean \pm SEM ( $n=10$ samples; one sample from one fish). ${ }^{*}$ indicates statistically significant difference at $P<0.01$ from the values in the control

eight scales for TRAP analysis by $2.5 \mathrm{ppm}$, (4) eight scales for ALP analysis by $0.025 \mathrm{ppm}$, (5) eight scales for ALP analysis by $0.25 \mathrm{ppm}$, and (6) eight scales for ALP analysis by $2.5 \mathrm{ppm}$. The respective mean for TRAP (obtained from eight individual scales of one goldfish) and ALP (obtained from eight individual scales of one goldfish) activities from the left side (experimental group) was compared with those of the right side (control group). Using 10 individual goldfish, the same experiment was done repeatedly. The experiments for 0.25 and $2.5 \mathrm{ppm}$ PCB (118) were carried out in the same manner. After incubation, TRAP and ALP activities were measured using the same methods described above (Suzuki et al. 2009). The results are shown as means $\pm \operatorname{SEM}(n=10)$.

Changes in TRAP, cathepsin $\mathrm{K}$, and RANKL mRNA expressions in PCB (118)-treated goldfish scales (in vitro experiment)

Scales were collected from goldfish under anesthesia with ethyl 3-aminobenzoate and methanesulfonic acid salt (Sigma-
Aldrich). To examine changes in TRAP, cathepsin $\mathrm{K}$, and RANKL mRNAs that responded to PCB (118), these scales were incubated for $18 \mathrm{~h}$ in Leibovitz's L-15 medium (Invitrogen) containing a $1 \%$ penicillin-streptomycin mixture (ICN Biomedicals). In the prostaglandin $\mathrm{E}_{2}$-treated scales of goldfish, we previously reported that TRAP, cathepsin $\mathrm{K}$, and RANKL mRNA expression increased at $18 \mathrm{~h}$ of incubation (Omori et al. 2012). Therefore, this incubation period was adopted. After incubation, the scales were frozen at $-80{ }^{\circ} \mathrm{C}$ for mRNA analysis.

Total RNAs were prepared from goldfish scales using a total RNA isolation kit for fibrous tissue (Qiagen $\mathrm{GmbH}$, Hilden, Germany). Complementary DNA synthesis was performed using a kit (Qiagen $\mathrm{GmbH}$ ). Gene-specific primers for TRAP (sense, 5'-AACTTCCGCATTCCTCGAACAG-3'; antisense, 5'-GGCCAGCCACCAGGAGATAA-3') (Azuma et al. 2007), cathepsin K (sense, 5'-GCTATGGAGCCACACCAAAAGG3'; antisense, 5'-CTGCGCTTCCAGCTCTCACAT-3') (Azuma et al. 2007), and RANKL (sense, 5'-GCGCTTACC TGCGGAATCATATC-3'; antisense, 5'-AAGTGCAACAG AATCGCCACAC-3') (Suzuki et al. 2011a) were used. The amplification of $\beta$-actin cDNA using a primer set $\left(5^{\prime}\right.$, CGAGCGTGGCTACAGCTTCA; 3', GCCCGTCAG GGAGCTCATAG) (Azuma et al. 2007) was performed. The PCR amplification was analyzed by real-time PCR apparatus (Mx3000p; Agilent Technologies, CA, USA) (Suzuki et al. 2011a). The annealing temperature of TRAP, cathepsin K, RANKL, and $\beta$-actin was $60{ }^{\circ} \mathrm{C}$. The TRAP, cathepsin $\mathrm{K}$, and RANKL mRNA levels were normalized to the $\beta$-actin mRNA level.

\section{Statistical analysis}

All results are expressed as the means $\pm \operatorname{SE}(n=10)$. The statistical significance between control and experimental group was assessed by Student's $t$ test (in vivo experiment) or paired $t$ test (in vitro experiment). In all cases, the selected significance level was $P<0.05$.
Fig. 3 Effects of PCB (118) administration on TRAP (a) and ALP (b) activities in the scales of goldfish at the $6 \mathrm{~h}$ of incubation. Each column and the vertical line represent the mean $\pm \operatorname{SEM}(n=10$ samples; one sample from one fish). * indicates statistically significant difference at $P<0.05$ from the values in the control a) TRAP activity

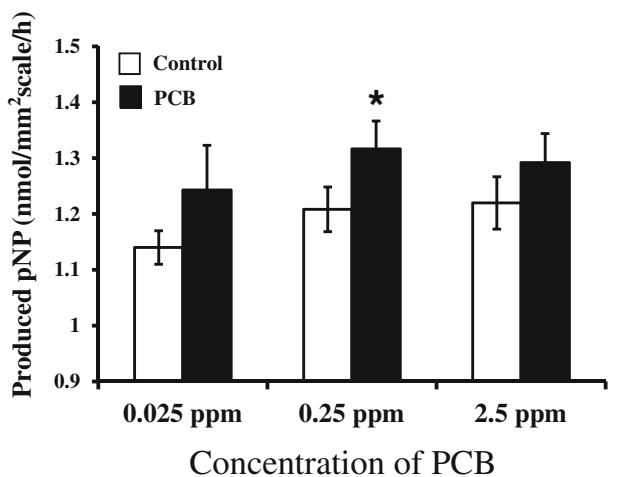

b) ALP activity

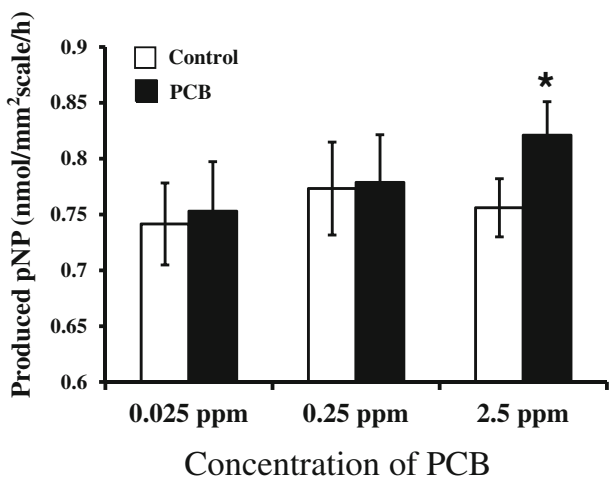


Fig. 4 Effects of PCB (118) administration on TRAP (a) and ALP (b) activities in the scales of goldfish at the $18 \mathrm{~h}$ of incubation. Each column and the vertical line represent the mean $\pm \operatorname{SEM}(n=10$ samples; one sample from one fish). * and *** indicate statistically significant differences at $P<0.05$ and $P<0.001$, respectively, from the values in the control

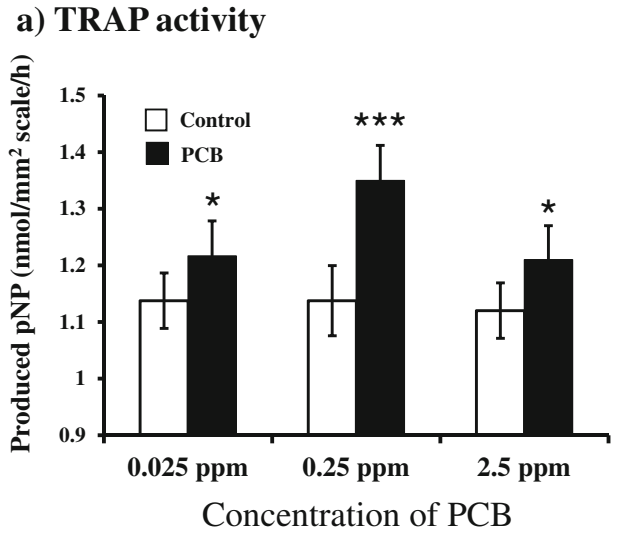

b) ALP activity

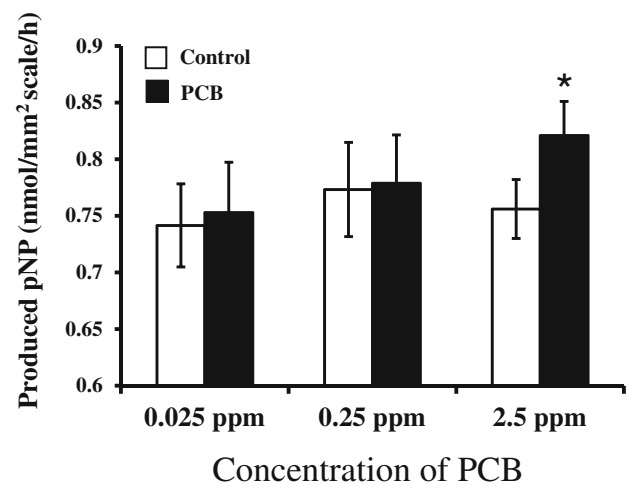

\section{Results}

Effects of PCB (118) on scale osteoclastic and osteoblastic activities and the plasma calcium in goldfish at 1 and 2 days after PCB (118) injection in vivo

We measured the activities of ALP and TRAP activities as respective indicators of each activity in osteoclasts and osteoblasts. At day 2, scale TRAP activity in PCB-injected goldfish increased significantly (Fig. 1a), while ALP activity did not change significantly at day 1 and 2 (Fig. 1b). Corresponding to the elevation of osteoclastic activity, plasma calcium levels increased significantly at day 2 after PCB administration (Fig. 2).

PCB (118) contents in the scales of goldfish in vivo

At day 1 and 2 after PCB (118) injection, PCB (118) was detected in the scales. At day 1, PCB contents in the control and PCB-injected scales were determined as 0.39 and 79 (ng/g-wet), respectively. At day 2, PCB (ng/g-wet) of 0.38 and 55 was detected in the control and PCBinjected scales, respectively.
Effect of PCB (118) on osteoclastic and osteoblastic activities in the cultured scales of goldfish in vitro

PCB (118) significantly increased the TRAP activities of the scales by $6 \mathrm{~h}$ of incubation $(P<0.05$ for $0.25 \mathrm{ppm})$ (Fig. 3a). At $18 \mathrm{~h}$ of incubation, the TRAP activities in the PCB (118)treated scales also significantly increased $(P<0.05$ for 0.025 and $2.5 \mathrm{ppm} ; P<0.001$ for $0.25 \mathrm{ppm}$ ) (Fig. $4 \mathrm{a}$ ).

In case of the ALP activities, it significantly increased $(P<0.05)$ only by the concentration of $2.5 \mathrm{ppm}$ at the 6 and $18 \mathrm{~h}$ incubation (Figs. $3 \mathrm{~b}$ and $4 \mathrm{~b}$ ).

Changes in TRAP, cathepsin $\mathrm{K}$, and RANKL mRNA expressions in PCB (118)-treated goldfish scales in vitro

The mRNA expression of osteoclastic markers (TRAP and cathepsin K) increased significantly by PCB (118) $(0.25 \mathrm{ppm})$ treatment (Fig. 5a, b).

Similar results were obtained in RANKL. The mRNA expression of RANKL, an activating factor of osteoclasts, increased significantly in the osteoblasts in the PCB (118)treated scales (Fig. 5c).

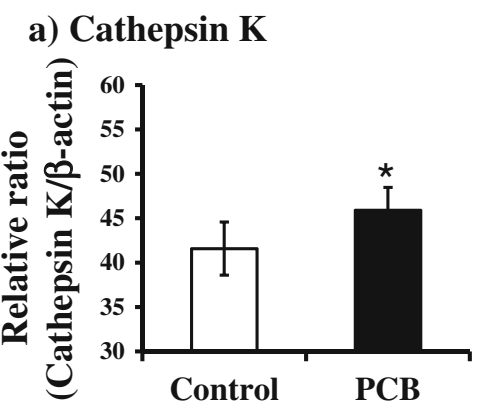

Fig. 5 Effect of PCB (118) (0.25 ppm) in the expression of osteoclastic markers: cathepsin K (a), TRAP (b), and RANKL (c) mRNAs in the scale. The cathepsin K, TRAP, and RANKL mRNA levels were normalized by the $\beta$-actin mRNA level. The values of ordinate indicate relative ratio of cathepsin $\mathrm{K} / \beta$-actin (a), TRAP/ $\beta$-actin (b), and

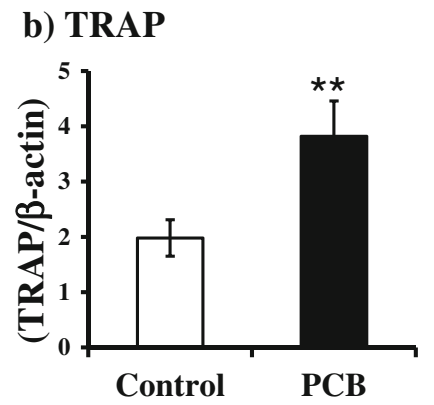

c) RANKL

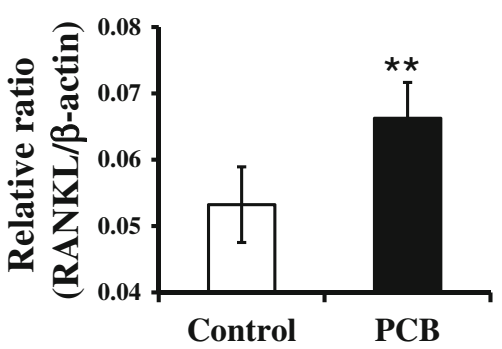

RANKL/ $\beta$-actin (c), respectively. Each column and the vertical line represent the mean \pm SEM ( $n=10$ samples; one sample from one fish). * and ** indicate statistically significant differences at $P<0.05$ and $P<0.01$, respectively, from the values in the control 


\section{Discussion}

In the present study, we are the first to demonstrate that PCB (118) induced hypercalcemia resulting from increasing osteoclastic activity in vivo. In an in vitro experiment, the data were reproduced and osteoclastic marker mRNA expression as well as enzyme activity increased. In fish, PCB (118) is the highest congener compared with PCB-105, -156, -167, $123,-157,-114,-189,-77,-126,-81$, or -169 (Bhavsar et al. 2007). In aquatic environment, PCB (118) was detected (Hope 2008; Aksoy et al. 2011). Therefore, we paid attention to bone metabolism by PCB (118) pollution.

At day 1 and 2 after PCB (118) injection intraperitoneally, we detected PCB (118) in the scale. As described in the "Introduction", the scales are potential internal calcium reservoir than the body skeletons, jaws, and otoliths. Lake et al. (2006) reported that the correlation between the total mercury concentration of the scales and that of the muscles was high ( $r=$ 0.89). In sheep, PCB was accumulated and detected in bone at 2 months after administration (Jan et al. 2006). We therefore suggest that scale PCB content can be used as an environmental PCB monitor to estimate the environmental pollution of PCB.

In the present study, we measured hydroxy-PCB which is a kind of metabolites from PCB because hydroxy-PCB possessed specific and competitive interactions with the plasma thyroid hormone transport protein, transthyretin (Lans et al. 1993). In PCB-treated scales, however, hydroxyl-PCB was not detected. Therefore, this phenomenon of osteogenesis seems to be direct action of PCB (118).

In an in vivo experiment, osteoblastic activity increased by the high concentration of PCB (118) (2.5 ppm). This indicates that PCB (118) is affected on osteoblasts. Osteogenesis is regulated by osteoblasts (Suda et al. 1999; Teitelbaum 2000; Lacey et al. 2012). RANKL produced by cells in the osteoblast lineage binds to the receptor activator of NF- $\mathrm{KB}$ (RANK) in mononuclear hemopoietic precursors and promotes the formation and activity of multinucleated osteoclasts (Suda et al. 1999; Teitelbaum 2000; Lacey et al. 2012). Our present study indicated that RANKL mRNA expression was promoted by PCB (118) treatment. In addition, osteoclastic marker (TRAP and cathepsin K) mRNA expression also increased significantly. Therefore, we strongly suggest that PCB (118) promotes osteoclastogenesis by the RANK-RANKL pathway.

In the present study, we succeeded to analysis the PCB (118) on osteoclasts and osteoblasts. Our results suggest that scale is a good model for analysis of bone metabolism. We previously demonstrated that the osteogenesis of regenerating scale is very similar to that of mammalian membrane bone and a good model of osteogenesis (Yoshikubo et al. 2005). Using this system, furthermore, we first demonstrated that calcitonin, a hypocalcemic hormone, suppressed osteoclastic activity in teleosts as well as in mammals (Suzuki et al. 2000) and that melatonin, a major hormone secreted from the pineal gland, suppressed the functions in both osteoclasts and osteoblasts (Suzuki and Hattori 2002). Osteoblasts in the scale responded to estrogen as they do in mammalian bone (Yoshikubo et al. 2005). In addition, the effects of endocrine disrupters, such as bisphenol-A (Suzuki and Hattori 2003) and tributyltin (Suzuki et al. 2006), and heavy metals, i.e., cadmium and mercury (Suzuki et al. 2004b, 2011b), on osteoblasts and osteoclasts have been examined. Moreover, we indicated that cadmium (even at $10^{-13} \mathrm{M}$ ) responded to TRAP activity in the scale (Suzuki et al. 2004b).

In conclusion, PCB (118) disrupts bone metabolism in goldfish both in vivo and in vitro experiments. Our results suggest that PCB (118) promotes osteoclastogenesis by the RANK-RANKL pathway. Furthermore, our previous and present results indicate that the scale assay system will be useful for the analysis of environmental contaminant on bone metabolism, and findings of PCB (118) on bone in fish may be tied in to an overall health issue for mammals in general.

Acknowledgments This study was supported in part by grants to N.S. [Kurita Water and Environment Foundation; Grant-in-Aid for Space Utilization by the Japan Aerospace Exploration Agency; Grant-in-Aid for Scientific Research (C) Nos. 21500404 and 24620004 by JSPS], to A.H. [Grant-in-Aid for Scientific Research (C) Nos. 21570062 and 24570068 by JSPS], to K.K. [Grant-in-Aid for Scientific Research (C) Nos. 21500681 and 24500848 by JSPS], to T.S. [Grant-in-Aid for Young Scientists (B) Nos. 22770069 and 40378568 by JSPS], to Y.T. [Grant-in-Aid for Scientific Research (B) No. 24310046 by JSPS], to T.N. [Grant-in-Aid for Scientific Research (B) No. 21310027 by JSPS], to H.M. [Grant-in-Aid for Scientific Research (C) No. 23592727 by JSPS], and to K.H. [the Environment Research and Technology Development Fund (B-0905) sponsored by the Ministry of the Environment, Japan; Health, Labor Sciences Research Grants of the Ministry of Health, Labor and Welfare, Japan; Grant-in-Aids for Scientific Research (B) No. 21390034 and for Exploratory Research No.24651044 by JSPS].

Open Access This article is distributed under the terms of the Creative Commons Attribution License which permits any use, distribution, and reproduction in any medium, provided the original author(s) and the source are credited.

\section{References}

Aksoy A, Das YK, Yavuz O, Guvenc D, Atmaca E, Agaoglu S (2011) Organochlorine pesticide and polychlorinated biphenyls levels in fish and mussel in Van region, Turkey. Bull Environ Contam Toxicol 87:65-69

Azuma K, Kobayashi M, Nakamura M, Suzuki N, Yashima S, Iwamuro S, Ikegame M, Yamamoto T, Hattori A (2007) Two osteoclastic markers expressed in multinucleate osteoclasts of goldfish scales. Biochem Biophys Res Commun 362:594-600

Bereiter-Hahn J, Zylberberg L (1993) Regeneration of teleost fish scale. Comp Biochem Physiol 105A:625-641

Bhavsar SP, Fletcher R, Hayton A, Reiner EJ, Jackson DA (2007) Composition of dioxin-like PCBs in fish: an application for risk assessment. Environ Sci Technol 41:3096-3102 
Bovee TFH, Helsdingen RJR, Hamers ARM, Brouwer BA, Nielen MWF (2011) Recombinant cell bioassays for the detection of (gluco) corticosteroids and endocrine-disrupting potencies of several environmental PCB contaminants. Anal Bioanal Chem 401:873-882

Gutleb AC, Arvidsson D, Örberg J, Larsson S, Skaare JU, Aleksandersen M, Ropstad E, Lind PM (2010) Effects on bone tissue in ewes (Ovies aries) and their foetuses exposed to PCB 118 and PCB 153. Toxicol Lett 192:126-133

Hirai T, Fujimine Y, Watanabe S, Nakano T (2005) Congener-specific analysis of polychlorinated biphenyl in human blood from Japanese. Environ Geochem Health 27:65-73

Hodgson S, Thomas L, Fattore E, Lind PM, Alfven T, Hellström L, Håkansson H, Carubelli G, Fanelli R, Jarup L (2008) Bone mineral density changes in relation to environmental PCB exposure. Environ Health Perspect 116:1162-1166

Holliday DK, Holliday CM (2012) The effects of the organopollutant PCB 126 on bone density in juvenile diamondback terrapins (Malaclemys terrapin). Aquat Toxicol 109:228-233

Hope BK (2008) A model for the presence of polychlorinated biphenyls (PCBs) in the Willamette River Basin (Oregon). Environ Sci Technol 42:5998-6006

Jan J, Milka V, Azra P, Dominik G, Matjaž Z (2006) Distribution of organochlorine pollutants in ovine dental tissues and bone. Environ Toxicol Pharmacol 21:103-107

Ju L, Tang K, Guo XR, Yang Y, Zhu GZ, Lou Y (2012) Effects of embryonic exposure to polychlorinated biphenyls on zebrafish skeletal development. Mol Med Report 5:1227-1231

Lacey DL, Boyle WJ, Simonet WS, Kostenuik PJ, Dougall WC, Sullivan JK, Martin JS, Dansey R (2012) Bench to bedside: elucidation of the OPG-RANK-RANKL pathway and the development of denosumab. Nat Rev Drug Discov 11:401-419

Lake JL, Ryba SA, Serbst JR, Libby AD (2006) Mercury in fish scales as an assessment method for predicting muscle tissue mercury concentrations in largemouth bass. Arch Environ Contam Toxicol 50:539-544

Lans MC, Klasson-Wehler E, Willemsen M, Meussen E, Safe S, Brouwer A (1993) Structure-dependent, competitive interaction of hydroxypolychlorobiphenyls, -dibenzo-p-dioxins and -dibenzofurans with human transthyretin. Chem Biol Interact 88:7-21

Lind PM, Eriksen EF, Lind L, Örberg J, Sahlin L (2004a) Estrogen supplementation modulates effects of endocrine disrupting pollutant PCB126 in rat bone and uterus diverging effects in ovariectomized and intact animals. Toxicology 199:129-136

Lind PM, Milnes MR, Lundberg R, Bermudez D, Örberg J, Guillette LJ Jr (2004b) Abnormal bone composition in female juvenile American alligators from a pesticide-polluted lake (Lake Apopka, Florida). Environ Health Perspect 112:359362

Mugiya Y, Watabe N (1977) Studies on fish scale formation and resorption II: effect of estradiol on calcium homeostasis and skeletal tissue resorption in the goldfish, Carassius auratus, and the killifish, Fundulus heteroclitus. Comp Biochem Physiol 57A:197-202

Nakayama K, Sei N, Handoh IC, Shimasaki Y, Honjo T, Oshima Y (2011) Effects of polychlorinated biphenyls on liver function and sexual characteristics in Japanese medaka (Oryzias latipes). Mar Pollut Bull 63:366-369

Nishimoto SK, Araki N, Robinson FD, Waite JH (1992) Discovery of bone $\gamma$-carboxyglutamic acid protein in mineralized scales. J Biol Chem 267:11600-11605

Ohira Y, Shimizu M, Ura K, Takagi Y (2007) Scale regeneration and calcification in goldfish Carassius auratus: quantitative and morphological processes. Fisheries Sci 73:46-54

Olufsen M, Arukwe A (2011) Developmental effects related to angiogenesis and osteogenic differentiation in salmon larvae continuously exposed to dioxin-like 3,3',4,4'-tetrachlorobiphenyl (congener 77). Aquat Toxicol 105:669-680

Omori K, Wada S, Maruyama Y, Hattori A, Kitamura K, Sato Y, Nara M, Funahashi H, Yachiguchi K, Hayakawa K, Endo M, Kusakari R, Yano S, Srivastav AK, Kusui T, Ejiri S, Chen W, Tabuchi Y, Furusawa Y, Kondo T, Sasayama Y, Nishiuchi T, Nakano M, Sakamoto T, Suzuki N (2012) Prostaglandin $E_{2}$ increases both osteoblastic and osteoclastic activities in the scales of goldfish and participates in the calcium metabolism in goldfish. Zool Sci 29:499-504

Onozato H, Watabe N (1979) Studies on fish scale formation and resorption III: fine structure and calcification of the fibrillary plates of the scales in Crassius auratus (Cypriniformes: Cyprinidae). Cell Tissue Res 201:409-422

Peacock M (2010) Calcium metabolism in health and disease. Clin J Am Soc Nephrol 5:S23-S30

Sonne C, Dietz R, Born EW, Riget FF, Kirkegaard M, Hyldstrup L, Letcher RJ, Muir DCG (2004) Is bone mineral composition disrupted by organochlorines in east Greenland polar bears (Ursus martitimus)? Environ Health Perspect 112:1711-1716

Suda T, Takahashi N, Udagawa N, Jimi E, Gillespie MT, Martin TJ (1999) Modulation of osteoclast differentiation and function by the new members of the tumor necrosis factor receptor and ligand families. Endocr Rev 20:345-357

Suzuki N, Hattori A (2002) Melatonin suppresses osteoclastic and osteoblastic activities in the scales of goldfish. J Pineal Res $33: 253-258$

Suzuki N, Hattori A (2003) Bisphenol A suppresses osteoclastic and osteoblastic activities in the cultured scales of goldfish. Life Sci 73:2237-2247

Suzuki N, Suzuki T, Kurokawa T (2000) Suppression of osteoclastic activities by calcitonin in the scales of goldfish (freshwater teleost) and nibbler fish (seawater teleost). Peptides $21: 115-124$

Suzuki N, Yamamoto K, Sasayama Y, Suzuki T, Kurokawa T, Kambegawa A, Srivastav AK, Hayashi S, Kikuyama S (2004a) Possible direct induction by estrogen of calcitonin secretion from ultimobranchial cells in the goldfish. Gen Comp Endocrinol 138:121-127

Suzuki N, Yamamoto M, Watanabe K, Kambegawa A, Hattori A (2004b) Both mercury and cadmium directly influence calcium homeostasis resulting from the suppression of scale bone cells: the scale is a good model for the evaluation of heavy metals in bone metabolism. J Bone Miner Metab 22:439-446

Suzuki N, Tabata MJ, Kambegawa A, Srivastav AK, Shimada A, Takeda H, Kobayashi M, Wada S, Katsumata T, Hattori A (2006) Tributyltin inhibits osteoblastic activity and disrupts calcium metabolism through an increase in plasma calcium and calcitonin levels in teleosts. Life Sci 78:2533-2541

Suzuki N, Kitamura K, Nemoto T, Shimizu N, Wada S, Kondo T, Tabata MJ, Sodeyama F, Ijiri K, Hattori A (2007) Effect of vibration on osteoblastic and osteoclastic activities: analysis of bone metabolism using goldfish scale as a model for bone. Adv Space Res 40:1711-1721

Suzuki N, Kitamura K, Omori K, Nemoto T, Satoh Y, Tabata MJ, Ikegame M, Yamamoto T, Ijiri K, Furusawa Y, Kondo T, Takasaki I, Tabuchi Y, Wada S, Shimizu N, Sasayama Y, Endo M, Takeuchi T, Nara M, Somei M, Maruyama Y, Hayakawa K, Shimazu T, Shigeto Y, Yano S, Hattori A (2009) Response of osteoblasts and osteoclasts in regenerating scales to gravity loading. Biol Sci Space 23:211-217

Suzuki N, Danks JA, Maruyama Y, Ikegame M, Sasayama Y, Hattori A, Nakamura M, Tabata MJ, Yamamoto T, Furuya R, Saijoh K, Mishima H, Srivastav AK, Furusawa Y, Kondo T, Tabuchi Y, Takasaki I, Chowdhury VS, Hayakawa K, Martin TJ (2011a) Parathyroid hormone 1 (1-34) acts on the scales 
and involves calcium metabolism in goldfish. Bone 48:11861193

Suzuki N, Yachiguchi K, Hayakawa K, Omori K, Takada K, Tabata JM, Kitamura K, Endo M, Wada S, Srivastav AK, Chowdhury VS, Oshima Y, Hattori A (2011b) Effects of inorganic mercury on osteoclasts and osteoblasts of the goldfish scales in vitro. J Fac Agr Kyushu Univ 56:47-51

Teitelbaum SL (2000) Bone resorption by osteoclasts. Science 289: 1504-1508

Thamamongood TA, Furuya R, Fukuba S, Nakamura M, Suzuki N, Hattori A (2012) Expression of osteoblastic and osteoclastic genes during spontaneous regeneration and autotransplantation of goldfish scale: a new tool to study intramembranous bone regeneration. Bone 50:1240-1249

Yoshikubo H, Suzuki N, Takemura K, Hoso M, Yashima S, Iwamuro S, Takagi Y, Tabata MJ, Hattori A (2005) Osteoblastic activity and estrogenic response in the regenerating scale of goldfish, a good model of osteogenesis. Life Sci 76:2699-2709

Zylberberg L, Bonaventure J, Cohen-Solal L, Hartmann DJ, Bereiter-Hahn J (1992) Organization and characterization of fibrillar collagens in fish scales in situ and in vitro. J Cell Sci 103:273-285 